\title{
Global Adjustment among First Year MBBS Students in Mandya Institute of Medical Sciences, Karnataka
}

\author{
Rekha. M. C ${ }^{1}$, NarashimhaSwamy. $\mathbf{P}^{2}$, Ravikumar. M. $\mathbf{B}^{3}$. \\ ${ }^{1}$ Associate Professor, Department of Medicine, Mandya Institute of Medical Sciences, \\ Mandya, Karnataka, India. \\ ${ }^{2}$ Professor and HOD, Department of Surgery, Mandya Institute of Medical Sciences, \\ Mandya, Karnataka, India. \\ ${ }^{3}$ Counsellor, ART Centre, Mandya Institute of Medical Sciences, Mandya, \\ Karnataka, India.
}

*Corresponding Author: Rekha. M. C, Associate Professor, Department of Medicine, Mandya Institute of Medical Sciences, Mandya, Karnataka, India.

\begin{abstract}
Background: The medical students undergo tremendous stress and adjustment during their course, may it be entrance exams, staying in hostel, new environment, heavy course, academic pressure, social issues and financial problems. Hence this study is proposed to find out stressors and maladjustment to suggest possible solutions.

Material and Methods: This cross-sectional study was conducted at MIMS; Mandya which included first year MBBS students and data was collected after obtaining approval from the institutional ethical committee, MIMS. A written informed consent was taken from the students. Personal information sheet consisting of 80 questions from the global adjustment scale designed by Sanjay Vohra (2013) was given all the students. After completion of the questions, the scoring was done and analyzed by SPSS version 21. Those who were not willing to participate were excluded from the study.

Results: Results showed that first year Male Medical students had higher emotional and social adjustments problems compared to Females. Family adjustment and health adjustment of first year male medical students and Female medical students did not show statistically significant difference. Medical Students coming from urban \& rural areas did not show statistically significant difference in family, health, social and emotional adjustments.

Conclusion: This study found a substantial number of medical students in the study sample showed emotional and social adjustment problems, more common in male students than female students. There was no region difference (rural/urban) among first year students. It is important to detect and correct these problems at an early stage, in order to provide interventional measures, prevent further complications, as well as to promote the wellbeing of medical students and future doctors.
\end{abstract}

Keywords: Global adjustment, First Year Medical Students, Gender.

\section{INTRODUCTION}

The transition from Pre-University to University is an exciting experience for some students but it is an overwhelming and stressful experience for others. Enrolling into medical school is entering a stressful environment that often leads to poor academic performance, psychological, physical and adjustment problems. Maladjustment is a major problem that leads students to discontinue their university programmes. Students commonly face the distress during their first year of medical school and attrition is usually highest. Maladjustment to the university may result in adjustment problems leading to students exhibiting negative emotional symptoms of depression, anxiety, and stress and it is more among females compared to males.

It is observed that medical students undergo tremendous stress during their course, may it be entrance exams, staying in hostel, new environment, heavy course, academic pressure social issues and financial problems. Hence this 
study is proposed to find out maladjustment and stressors to suggest possible solutions.

The term "adjustment" refers to the adequacy of the personal and interpersonal process that we use to adapt to our environment. There is no way to define a good or a poor adjustment without the use of certain basis that we and others have for what represents appropriate behaviours. Any individual at any given time is dealing with himself or his environment.

The term adjustment is often used as a synonym for accommodation and adaptation. Strictly speaking, the term denotes the results of equilibrium, which may be affect by either of these processes (Monroe, 1990). It is used to emphasize the individuales struggle to along or survive in his or her social and physical environment. Adjustment is a process by which a living organism maintains a balance between its needs and the circumstances that influence the satisfaction of these needs. Adjustment is harmonious relationship with the environment involving the ability to satisfy most of one $\mathrm{s}$ needs and most of the demands, both physical and social that are put upon one (Anonymous, 1968).

Adjustment is a built - in mechanism for coping with the problematic or other realities of life. Adjustment has been considered as an index to integration; a harmonious behaviour of the individual by which other individual of society recognise person is well adjusted (Pathak, 1990). In the modern society, life is becoming very complex and conflicting day by day. If a person is well adjusted, only then one can survive without psychological stress resulting from maladjustment. Hence adjustment is important in one"s life. Adjustment during the period of students will determine to a larger extent what will one be as a person as an adult. Generally students is believed to be a period of great stress and storm as rapid physical as well as mental changes occur during this period. Every cultural group has expectations of an individual according to their developmental stage. Successful achievement of such developmental tasks leads to happiness and help to succeed in later tasks, failure to unhappiness and a developmental lag. Certain developmental tasks to be achieved during adolescence are: Achieving more mature relations with age mates, Learning to perform a masculine or feminine social role, Accepting one and using the body effectively, Achieving emotional independence of parents and other adults, Preparing for economic independence, Achieving socially responsible behaviour and Acquiring a set of values as a guide to behaviour Attainment of these developmental tasks helps adolescents to lay foundation for a successful adjustment in adulthood.

According to Aggrawal (2004) the adjustment of adolescent very much depends on the fulfilment of their significant specific needs that consist of physical needs, emotional needs, social needs, and intellectual needs, moral needs and vocational needs. It may be helpful, therefore, to devote a little more space to two important qualities of adjustment. First, it is a process that involves continuous changes and the second people develop consistent pattern of adjustment to these constant changes. Students make many transitions during their years of schooling: from home to school, middle to high school, and high school to college or work. These transitions are usually major events in the lives of students and parents. The stresses created by these transitions can be minimized when the new environment is responsive to each particular age group. This digest presents a brief overview of some of the issues involved in the transition from elementary to middle school and provide suggestions for transition programs and activities. In a study Isakson et al, (1999) employed a short term longitudinal design to assess the adjustment of adolescents as they mode from junior high to high school and found that the adolescents did experience significant changes during the initial transition into high school that were related to sense of school membership, perceived support from parents was also related to adolescents adjustment to the transition.

Young people go through a transition in teenage years and one of the biggest issues they will face affecting mental health and social identity. They experience all sorts of pressures, difficulties and circumstances such as peer pressure, moving to a new school, breaking relationships with friends, arguments with parents, struggle for autonomy, exams, not feeling good enough, changing or chaotic home environment, exam pressure and failures and above all pubertal changes, school exclusion or truancy. Cairns and Lloyd (2005) extracted data from the young life and times survey in Northern Ireland and reported that school work and exams was the most cited cause of stress for young people of 16 years old. Anonymous (2004) has examined 
Global Adjustment among First Year MBBS Students in Mandya Institute of Medical Sciences, Karnataka

trends between 1983 and 2003 in young peoplees emotional health and well being, as reported through their young people and health survey and has found that young people are increasingly more likely to worry quite a lot about school and career problems

Adolescents have a poor reputation of getting along poorly with their families. The teenage boy or girl may be faced with serious problems of adjustment when there is a difference of opinions, ideals and attitudes with their parents. Conflicts may arise between the adolescent and the parents that are difficult to resolve if neither is willing nor able to compromise. It takes all the tact and understanding of parents to handle their teenage son or daughter (Coleman, 1974). Families of delinquent or uncontrollable adolescents are characterized by poorer family relationships and less social connectedness. In general, these families are lower on cohesion and independence and higher on conflict and control (Fox et al., 1983). The family environment also affects the academic achievement, which is the product of maturational forces within the adolescent and the experiences provided by the environment (Bernard, 1971). A study by Nihiral et al., (1985) has revealed significant influences of changes in home environment on social adjustment in adolescent.

The present study is taken up at Mandya Institute of Medical Sciences, Mandya to know the different variables of adjustment in global adjustment scale. This makes the students enjoy their medical education with good adjustment to the medical college environment. The study participants included first year MBBS students, both Males and Females. Those who were not willing to participate were excluded from the study. All the first year MBBS students were given personal information sheets consisting of 80 questions from the global adjustment scale designed by Sanjay Vohra (2013).Written informed consent was taken to participate in the study. After completion of the questions the scoring was done and analyzed by SPSS version 21.

\section{Objectives}

1. To study the adjustment problems of male and female First year MBBS students.

2. To study the adjustment problems of rural and urban First year MBBS students.

\section{Materials AND MeTHOdS}

A clinical based study conducted during August 2016 in Mandya Institute of Medical Sciences, Mandya, Karnataka. The sample consists of total 85 students among them 40 were Male and 45 were Female (including 63urban and 22 rural students). For sample selection purposive sampling method was used. The age ranges from 18 to 21 years and the mean age was 19.5 years and data was collected after obtaining approval from the institutional ethical committee, MIMS, Mandya.

Global Adjustment Inventory developed by Sanjay Vohra (2013) was given all the students. It consists of 80 items which measure adjustment in four different areas namely Emotional adjustment, Family adjustment, Health adjustment and Social adjustment with 20 items each. The reliability and validity of the test was satisfactory. The higher score indicates the higher adjustment problems.

\section{Procedure}

After establishing rapport with the Subjects, the researcher asked to introduce themselves. The purpose and nature of the study was made clear to them. They were asked to give their sociodemographic details in the prescribed proforma. Then they were administered the Adjustment Inventory in the group of members. They were given appropriate instructions and the questions were read out to them. They were asked to indicate their responses in the answer sheets given to them. Whenever they had doubt in understanding items, the test administrator clarified their doubts in their local language. Data collection was done in one session and the session lasted for about 45-60 minutes approximately. Then the data was scored and statistically analysed by using descriptive and $\mathrm{t}$ test.

\section{RESULTS AND DISCUSSION}

Table1. Shows mean SD and't' values for Emotional, Family, Health and Social adjustment of Male and Female first year Medical students.

\begin{tabular}{|c|c|c|c|c|c|c|}
\hline Domains & Gender & $\mathbf{N}$ & Mean & SD & $\mathbf{T}$ & P \\
\hline Emotional & Male & 40 & 25.25 & 5.537 & \multirow{2}{*}{2.770} & \multirow{2}{*}{.007} \\
\cline { 2 - 6 } & Female & 45 & 21.98 & 5.345 & & \\
\hline Family & Male & 40 & 26.08 & 4.305 & \multirow{2}{*}{1.514} & \multirow{2}{*}{.134} \\
\cline { 2 - 6 } & Female & 45 & 24.91 & 2.678 & & \\
\hline \multirow{2}{*}{ Health } & Male & 40 & 22.75 & 3.217 & \multirow{2}{*}{.008} & \multirow{2}{*}{.994} \\
\cline { 2 - 6 } & Female & 45 & 22.76 & 3.556 & & \\
\hline \multirow{2}{*}{ Social } & Male & 40 & 26.43 & 5.560 & \multirow{2}{*}{2.486} & \multirow{2}{*}{.015} \\
\cline { 2 - 5 } & Female & 45 & 23.20 & 6.312 & & \\
\hline Total & Male & 40 & 100.50 & 15.326 & & \multirow{3}{*}{020} \\
\cline { 2 - 5 } & Female & 45 & 92.84 & 14.303 & 2.382 & .020 \\
\hline
\end{tabular}


Global Adjustment among First Year MBBS Students in Mandya Institute of Medical Sciences, Karnataka

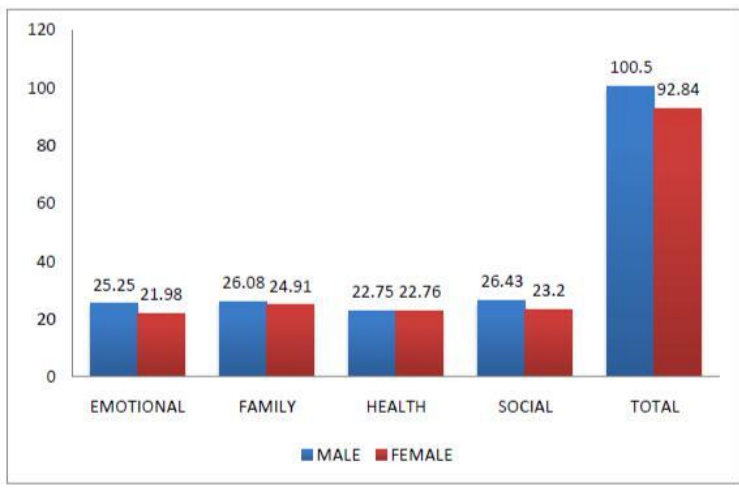

Figure1. Column graph showing mean scores in Emotional, Family, Health and Social adjustment of male and female first year Medical students.

Table No. 1 shows mean, SD and $\mathrm{t}$ values for Global adjustment among First year medical students. Emotional adjustment of First year Medical male students Mean= 25.25; $\mathrm{SD}=5.537$ and Female students Mean=21.98; $\mathrm{SD}=5.345$ $(\mathrm{t}=2.770 ; \mathrm{p}<.007)$ indicating highly significant difference. It can be said that first year medical male students were having higher emotional adjustment problems compared to female students.

Family adjustment of first year male medical students Mean= 26.08; $\mathrm{SD}=4.305$ and Female students Mean $=24.91 ; \mathrm{SD}=2.678 \quad(\mathrm{t}=1.514$; $\mathrm{p}>$.134) indicating no-significant difference. It can be said that I year medical male students and female students were not having any difference in family adjustment.

Health adjustment of first year male medical students Mean $=22.75 ; \mathrm{SD}=3.217$ and female students Mean $=22.76 ; \mathrm{SD}=3.556(\mathrm{t}=.0008$; $\mathrm{p}>$.994) indicating no-significant difference. It can be said that first year medical male students and female students were not having any difference in health adjustment.

Social adjustment of first year Male Medical students Mean $=26.43 ; \mathrm{SD}=5.560$ and Female students Mean= 23.20; $\mathrm{SD}=6.312 \quad(\mathrm{t}=2.486$; $\mathrm{p}<.015$ ) indicating highly significant difference. It can be said that first year male medical students were having higher Social adjustment problems comparing with female students.

Overall Global adjustment of first year Male Medical students Mean $=100.50 ; \mathrm{SD}=15.326$ and Female students Mean= 92.84; $\mathrm{SD}=14.303$ $(\mathrm{t}=2.382 ; \mathrm{p}<.020)$ indicating highly significant difference. It can be said that first year medical male students were having higher global adjustment problems comparing with female students.
Table2. Shows mean $S D$ and ' $t$ ' values for Emotional, Family, Health and Social adjustment of Urban and Rural first year Medical students.

\begin{tabular}{|c|c|c|c|c|c|c|}
\hline Domains & Domicile & $\mathbf{N}$ & Mean & SD & T & P \\
\hline Emotional & Urban & 63 & 23.84 & 5.734 & .893 & .374 \\
\cline { 2 - 6 } & Rural & 22 & 22.59 & 5.413 & & \\
\hline \multirow{2}{*}{ Family } & Urban & 63 & 25.41 & 3.675 & .201 & .841 \\
\cline { 2 - 6 } & Rural & 22 & 25.59 & 3.305 & & \\
\hline \multirow{2}{*}{ Health } & Urban & 63 & 22.90 & 3.305 & .699 & .487 \\
\cline { 2 - 6 } & Rural & 22 & 22.32 & 3.630 & & \\
\hline \multirow{2}{*}{ Social } & Urban & 63 & 24.51 & 6.037 & .530 & .598 \\
\cline { 2 - 5 } & Rural & 22 & 25.32 & 6.578 & & \\
\hline TOTAL & Urban & 63 & 96.67 & 15.279 & .224 & .823 \\
\cline { 2 - 5 } & Rural & 22 & 95.82 & 15.302 & & \\
\hline
\end{tabular}

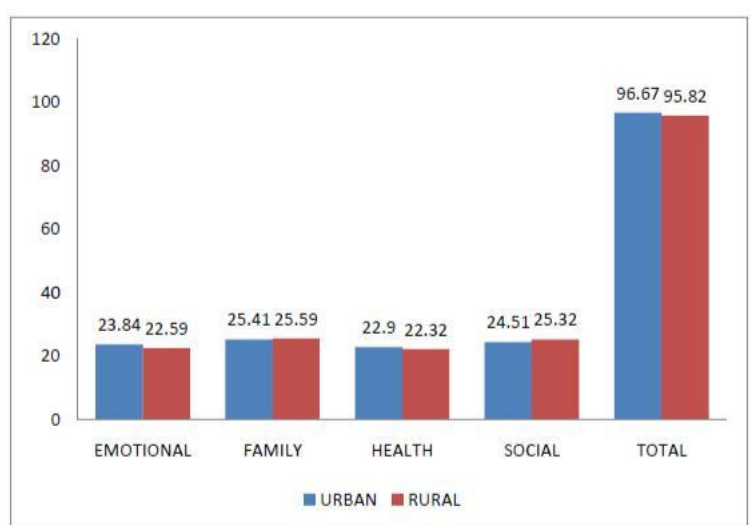

Figure2. Column graph showing mean scores in Emotional, Family, Health and Social adjustment of Urban and Rural first year Medical students.

Table No. 2 shows mean, SD and $t$ values for Global adjustment among first year medical students. Emotional adjustment of first year Medical Urban students Mean= 23.84; $\mathrm{SD}=$ 5.734 and Rural students Mean= 22.59; $\mathrm{SD}=$ $5.413(\mathrm{t}=.893 ; \mathrm{p}>.374)$ indicating no-significant difference. It can be said that first year urban medical students and rural students were statistically not having any difference in emotional adjustment.

Family adjustment of first year urban medical students Mean $=25.41 ; \mathrm{SD}=3.675$ and rural students Mean $=25.59 ; \mathrm{SD}=3.305 \quad(\mathrm{t}=.201$; p .841 ) indicating no-significant difference. It can be said that first year urban medical students and rural students were statistically not having any difference in family adjustment.

Health adjustment of first year urban medical students Mean $=22.90 ; \mathrm{SD}=3.305$ and rural students Mean $=22.32 ; \mathrm{SD}=3.630 \quad(\mathrm{t}=.699$; $\mathrm{p}>$.487) indicating no-significant difference. It can be said that first year urban medical students and rural students were statistically not having any difference in health adjustment. 
Global Adjustment among First Year MBBS Students in Mandya Institute of Medical Sciences, Karnataka

Social adjustment of first year urban Medical students Mean $=24.51 ; \mathrm{SD}=6.037$ and rural students Mean $=25.32 ; \mathrm{SD}=6.578(\mathrm{t}=.530$; p>.598) indicating no-significant difference. It can be said that first year urban medical students and rural students were statistically not having any difference in social adjustment.

Overall Global adjustment of first year urban Medical students Mean=96.67; $\mathrm{SD}=15.279$ and rural students $\mathrm{Mean}=95.82 ; \mathrm{SD}=15.302$ $(\mathrm{t}=.224 ; \quad \mathrm{p}>.823) \quad$ indicating no-significant difference. It can be said that first year urban medical students and rural students were statistically not having any difference in global adjustment.

\section{DISCUSSION}

The present study examined the relationship between the adjustment of first year MBBS students as well as their scores on the dimensions that is health, education, emotion, social aspects in relation to their emotional maturity. Table No. 1 and column graph 1 shows the mean, standard deviation and „te values for global adjustment among first year medical students. Emotional adjustments of first year medical male students, mean $=25.25$ $\mathrm{SD}=5.537$ and female students mean $=21.90$ $\mathrm{SD}=5.345(\mathrm{t}=2.770 ; \mathrm{P}>0.007)$ indicating highly significant difference. It can be said that first year medical male students had higher emotional adjustments problems compared to female students. This finding is similar to the study done by Dimpy Mahanta and Vikasni Kannan in Delhi University where male students had higher adjustment problems compared to female students.

According to Roslin Jose et al. $78.2 \%$ students had depression and adjustment score more than 49. In a study done in Sweden depression was $12.9 \%$. It was more among females as compared to males. In the Korean medical students, the prevalence of depression at the time of the study was $2.9 \%$, and females had more depression than males. In a study done by Basnet et al., among Nepali medical students, the overall prevalence of depression was $29.8 \%$.Among the medical students of Karachi prevalence of depression, adjustment and anxiety was $46.1 \%$.In a study done by Iqbal et al., the percentage of depression and adjustment among under-graduate medical students was $51.3 \%$, and it was more among 2nd year than 1st year students, which corroborates with the study. In a study done in Alexandria depression was 57.9\% and was highest among females.

Family adjustments and health adjustment were almost similar in male and female students indicating that there was no significant difference. Social adjustments of first year medical male students showed higher social adjustments problems comparing with female students. Overall global adjustment of first year medical students- male students had higher global adjustment problems comparing with female students.

Table no 2 and column graph no 2 shows. Mean scores in emotional, family, health and social adjustment of urban and rural students which showed that students coming from rural or urban region showed no significant difference in health, emotional, family, social and overall adjustment.

\section{CONCLUSIONS}

This study found that a substantial number of medical students in the study sample showed emotional and social adjustment problems, more common in male students than female students. There was no region difference (rural/urban) among first year students. It is important to detect and correct these problems at an early stage, in order to provide interventional measures, prevent further complications, as well as to promote the wellbeing of medical students and future doctors.

\section{REFERENCES}

[1] Aggrawal, J.C. (2004). Psychology of learning and Development, Shipra Publication, Delhi.

[2] Ajay. T Shendarkar, Vijay Patil. A study of stressors in medical college students (Hostilities) in northern Maharashtra. Journal of Indian academy of forensic medicine 2013 9.35(3).

[3] Anonymous, (1968). Dictionary of Behavioural Sciences. MacMillan, New York.

[4] Basnet B, Jaiswal M, Adhikari B, Shyangwa PM. Depression among undergraduate medical students. Kathmandu University Medical Journal (KUMJ) 2012; 10:56-9.

[5] Bernard, W. (1971). Adolescent Development. New York: Educational Publishers.

[6] Chitra Chatterjee, Pankaj K Mandal, Sarmila Mallik, Nirmalya Manna, Jadab C Sardar, Samir Dasgupta. A study on mental distress among 
Global Adjustment among First Year MBBS Students in Mandya Institute of Medical Sciences, Karnataka

MBBS students in a medical college, Kolkata. Annuals of tropical medicine and public health 2012: vol 5: 453-457.

[7] Coleman, C.J. (1974). Relationship in adolescence. London: Routledge \& Kegan Paul.

[8] Dimpy Mahanta, Vikasni Kannan. Emotional Maturity and Adjustment in First Year Undergraduates of Delhi University: An Empirical Study.

[9] Fox, R., Rotatori, A., \& Macklin, F. (1983).

Socially maladjusted adolescents ${ }^{\text {ee }}$ perception of their families. Psychological Reports. 52,831-834.

[10] Iqbal S, Gupta S, Venkatarao E. Stress, anxiety and depression among medical undergraduate students and their socio-demographic correlates. Indian J Med Res 2015; 141:354-7.

[11] Isakson, K. (1999). The adjustment of adolescents during the transition into high school: A shortterm longitudinal study. Journal of Youth and Adolescence, 28, 1-26.
[12] Jose R, Gore CA, Plathottam JJ, Priyanka MS, Nikitha HK. Depression and Insomnia among Medical Students in Bengaluru, India. International Journal Prevent Public Health Science 2016; 2(1):22-24.

[13] Monroe, P. (1990). International encyclopaedia of education, New Delhi: Cosmo Publications.

[14] Nihiral, K., Nink, I.T., \& Edward, M.C. (1985). Home environment and development of slow learning adolescents, reciprocal relations. Developmental Psychology. 21, 784-795.

[15] Primrose C. Nyamayaro, Coumarvelou Saravanan. The relation between adjustment and negative emotional states among first year medical students. Asian journal of social sciences and humanities 2013 August Vol.2.No.3.

[16] Seema Tanaji Methre, Nirmala G Borade, TanajiMethre. Perception of stress in First - year MBBS, BDS and BPTh students, National Journal of Psychology, Pharmacy and Pharmacology. 2017: vol 7, 2.

Citation: Rekha M, Narashimha Swamy P, Ravikumar M. Global Adjustment among First Year MBBS Students in Mandya Institute of Medical Sciences, Karnataka. International Journal of Research Studies in Medical and Health Sciences. 2017;2(4):11-16.

Copyright: (C) 2017 Rekha M, et al. This is an open-access article distributed under the terms of the Creative Commons Attribution License, which permits unrestricted use, distribution, and reproduction in any medium, provided the original author and source are credited. 